\title{
Carnitine supplementation to obese Zucker rats prevents obesity-induced type I to type II muscle fiber transition and favors an oxidative phenotype of skeletal muscle
}

\author{
Aline Couturier ${ }^{1}$, Robert Ringseis ${ }^{1}$, Frank-Christoph Mooren ${ }^{2}$, Karsten Krüger $^{2}$, Erika Most ${ }^{1}$ and Klaus Eder ${ }^{1 *}$
}

\begin{abstract}
Background: In the present study, we tested the hypothesis that carnitine supplementation counteracts obesityinduced muscle fiber transition from type I to type II.

Methods: 24 obese Zucker rats were randomly divided into two groups of 12 rats each (obese control, obese carnitine) and 12 lean Zucker rats were selected for lean control group. A control diet was given to both control groups and a carnitine supplemented diet ( $3 \mathrm{~g} / \mathrm{kg}$ diet) was given to obese carnitine group for $4 \mathrm{wk}$. Components of the muscle fiber transformation in skeletal muscle were examined.

Results: The plasma level of carnitine were lower in the obese control group compared to the lean control group and higher in the obese carnitine group than in the other groups $(P<0.05)$. Plasma concentrations of triglycerides and non-esterified fatty acids were increased in obese animals compared to lean animals and the obese carnitine group had lower level compared to the obese control group $(P<0.05)$. The obese carnitine group had an increased number of type I muscle fibers and higher mRNA levels of type I fiber-specific myosin heavy chain, regulators of muscle fiber transition and of genes involved in carnitine uptake, fatty acid transport, $\beta$-oxidation, angiogenesis, tricarboxylic acid cycle and thermo genesis in $M$. rectus femoris compared to the other groups $(P<0.05)$.

Conclusion: The results demonstrate that carnitine supplementation to obese Zucker a rat counteracts the obesityinduced muscle fiber transition and restores the muscle oxidative metabolic phenotype. Carnitine supplementation is supposed to be beneficial for the treatment of elevated levels of plasma lipids during obesity or diabetes.
\end{abstract}

Keywords: Carnitine, Zucker rat, Muscle fiber transition, Type I fiber, Oxidative capacity, Fatty acid oxidation

\section{Background}

The different contractile and metabolic functions of individual skeletal muscles in the body are caused by a different muscle fiber distribution. Two major types of muscle fibers, which differ in their myosin heavy-chain $(\mathrm{MHC})$ isoforms and their enzymatic capacity [1], can be distinguished. Type I fibers are mitochondria-rich, have a high oxidative capacity utilizing mostly oxidative phosphorylation [2,3], and are myoglobin-rich with red

\footnotetext{
* Correspondence: klaus.eder@ernaehrung.uni-giessen.de

${ }^{1}$ Institute of Animal Nutrition and Nutrition Physiology,

Justus-Liebig-University Giessen, Heinrich-Buff-Ring 26-32, 35390 Giessen,

Germany

Full list of author information is available at the end of the article
}

appearance. Type II fibers (subdivided in IIa, IIb and IId/x) have a lower oxidative capacity due to fewer mitochondria content than type I muscle fibers and thus depend on glycolytic metabolism to generate ATP.

Interestingly, muscle fiber distribution is altered by genetic and/or high fat diet-induced obesity due to induction of fiber transition from type I to type II thereby leading to a change of the muscle's metabolic phenotype [4-7]. The resulting reduced type I fiber content is associated with mitochondrial dysfunction characterized by an impaired mitochondrial oxidative enzyme capacity of skeletal muscle [8]. Noteworthy, genetic and/or high fat diet-induced obesity and diabetes cause an impairment of carnitine status [9-11], whereas normalization of 
carnitine status due to carnitine supplementation reverses mitochondrial dysfunction under these conditions $[4,9,10,12,13]$. At large, these findings indicate that carnitine supplementation through normalizing carnitine status is able to prevent type I to type II fiber transition and thereby the metabolic shift from oxidative to glycolytic of skeletal muscle under unloading conditions or metabolic stress.

Obesity- and diabetes-induced type I to type II fiber transition and decreases of oxidative capacity of skeletal muscle has been explained by down-regulation of peroxisome proliferator-activated receptor $\gamma$, coactivator- $1 \alpha$ $(\mathrm{PGC}-1 \alpha)$ and peroxisome proliferator-activated receptor $\delta$ (PPAR $\delta$ ) $[4,9,14]$. Both, PGC- $1 \alpha$ and PPAR $\delta$ are critical regulators of genes involved in type II to type I fiber transition, mitochondrial biogenesis, cellular and mitochondrial fatty acid uptake, $\beta$-oxidation, carnitine uptake, tricarboxylic acid cycle, respiratory chain, and angiogenesis [15-20]. Due to these functions PPAR $\delta$ and PGC- $1 \alpha$ are typically higher expressed in oxidative type I muscle fibers than in glycolytic type II muscle fibers $[15,21]$. Interestingly, carnitine supplementation was reported to increase expression of PGC- $1 \alpha$ and PPAR $\delta$ in rodent models of unloading [4], and genetic and dietinduced obesity and diabetes [10]. Based on these observations we hypothesized that carnitine supplementation through inducing PGC- $1 \alpha$ and PPAR $\delta$ in skeletal muscle counteracts obesity and/or diabetes-induced muscle fiber transition from type I to type II and restores the muscle fiber distribution and the muscle oxidative metabolic phenotype observed during non-obese and nondiabetic states. As a model object we used obese Zucker rats, an established genetic model of obesity, insulin resistance, and metabolic syndrome, which were fed either a carnitine supplemented or a control diet with a low native carnitine concentration for 4 wk. Lean Zucker rats served as healthy non-obese and non-diabetic controls.

\section{Methods}

\section{Animals and housing}

24 male obese (fa/fa) Zucker rats (Crl:ZUC-Lepr ${ }^{f a}$; Charles River, France) were randomly divided in two groups of 12 rats each. They had an initial body weight of $357 \pm 4$ (mean \pm SEM) g and aged 8-10 weeks. In addition, 12 male heterozygous lean $(\mathrm{fa} /+)$ Zucker rats were used for the lean control group. They were also 810 weeks old and had an initial body weight of $271 \pm 3$ (mean \pm SEM) g. The rats were kept in Macrolon cages in a controlled environment with a 12-h light-dark cycle. All experimental procedures followed established guidelines for the care and handling of laboratory animals and were approved by the local Animal Care and Use Committee.

\section{Diets and feeding}

The rats received two different semi-purified diets which were composed according to the recommendations of the American Institute of Nutrition (AIN)-93G [22]. The first diet, which contained no carnitine supplement and had a very low carnitine concentration of below $<5 \mathrm{mg}$ carnitine/kg diet, was given to the lean control and the obese control group. The second diet containing 3 g carnitine $/ \mathrm{kg}$ diet was given to the obese carnitine group. Both diets contained (g/kg diet): corn starch, 530; casein, 200; saccharose, 100; soybean oil, 70; cellulose, 50; minerals, 30; vitamins, 20. Carnitine was added to the obese carnitine diet at the expense of corn starch. The diets were prepared by mixing the dry components and subsequent pelleting using a standard pelleting device (Kahl Laborpressanlage Typ 14-175; Reinbek, Germany). Feed and water was available ad libitum and feed intake was recorded every week during the 28 days of the experiment.

\section{Sample collection}

The rats of all groups were decapitated under $\mathrm{CO}_{2}$ anesthesia. Blood samples were taken into EDTA polyethylene tubes (Sarstedt, Nürnbrecht, Germany) and plasma was collected by centrifugation $(1,100 \times$ g; $10 \mathrm{~min}, 4^{\circ} \mathrm{C}$ ). $M$. rectus femoris was excised, immediately snap-frozen with liquid nitrogen and stored at $-80^{\circ} \mathrm{C}$ pending analysis.

\section{Muscle fiber typing}

For muscle fiber typing serial cross-sections of $30 \mu \mathrm{m}$ thickness from $M$. rectus femoris were prepared using a cryostat microtome at $-25^{\circ} \mathrm{C}$ and muscle fibers were identified by their different inactivation of myofibrillar actomyosin ATPase during acid preincubation, using a modified method according to Hämäläinen and Pette [23], as recently described [24].

\section{Determination of plasma lipids}

The concentration of triglycerides in plasma was determined using enzymatic reagent kits (refs. 157609990314 and 113009990314) [25]. Concentration of non-esterified fatty acids (NEFA) in plasma was measured using the NEFA kit from Wako Chemicals (ref. RD291001200R).

\section{Determination of carnitine levels in plasma and muscle}

Tandem mass spectrometry was used for determining the concentrations of free carnitine and acetyl carnitine in plasma and muscle. Total carnitine was calculated as the sum of free carnitine and acetyl-carnitine. Deuterated carnitine-d3 (Cambridge Isotype Laboratories, Andover, MA, USA) was used as internal standard, according the method of Hirche et al. [26]. 


\section{RNA isolation and qPCR analysis}

Total RNA was isolated from $20 \mathrm{mg}$ skeletal muscle tissue using Trizol $^{\mathrm{TM}}$ reagent (Invitrogen, Karlsruhe, Germany) according to the manufacturer's protocol. Isolated RNA was stored at $-80^{\circ} \mathrm{C}$. RNA concentration and purity were estimated from the optical density at 260 and $280 \mathrm{~nm}$ (Infinite $200 \mathrm{M}$ micro plate reader, Tecan, Männedorf, Switzerland). The integrity of the RNA was also verified by $1 \%$ agarose gel electrophoresis, which showed intact bands corresponding to the $18 \mathrm{~S}$ and $28 \mathrm{~S}$ ribosomal RNA subunits. cDNA synthesis and qPCR analysis were performed as described recently in detail [27]. Features of gene-specific primer pairs are listed in Table 1. Calculation of gene expression data and normalization by GeNorm normalization factor were carried out as described recently [27]. In this study the three most stable out of six tested potential reference genes were CANX, TOP1 and YWHAZ in $M$. rectus femoris (Table 2). Means and SEM were calculated from normalized expression data for samples of the same treatment group. The mean of the control obese group was set to 1 and means and SEM of the other treatment groups were scaled proportionally. Data on qPCR performance for each gene measured in skeletal muscle are shown in Table 1.

\section{Western blotting}

Homogenates were prepared and protein concentration was determined as described recently [11]. After protein separation by $12.5 \%$ SDS-PAGE the proteins were transferred to a nitrocellulose membrane and incubated with primary antibodies against PGC- $1 \alpha$ (polyclonal antiPGC-1 $\alpha$ antibody; Millipore, Temecula, CA) and novel organic cation transporter 2 (OCTN2) (polyclonal antiOCTN2 antibody; Lifespan Bioscience, Inc., Seattle, US) and glyceraldehyde-3-phosphate dehydrogenase (GAPDH) (monoclonal anti-GAPDH antibody, Abcam, Cambridge, $\mathrm{UK})$ as a reference protein. The membranes were washed, and then incubated with a horseradish peroxidase conjugated secondary monoclonal anti-mouse-IgG antibody (Sigma-Aldrich, Steinheim, Germany) for GAPDH and polyclonal anti-rabbit-IgG antibody (DakoCytomation, Glostrup, Denmark) for PGC- $1 \alpha$ and OCTN2 at room temperature. Afterwards blots were developed by ECL Select (GE Healthcare, Munich, Germany) and the intensities of the specific bands were detected with a BioImaging system (Syngene, Cambridge, UK) and quantified by Syngene Gene Tools software (nonlinear dynamics).

\section{Statistics}

Statistical analysis of all data was done by one-way ANOVA using the Minitab Statistical Software (Rel. 13.0, State College, PA, USA). Means of the three groups were compared by Fisher's multiple range tests. Means were considered significantly different for $P<0.05$. Data presented are shown as means \pm SEM.

\section{Results}

Feed intake and body weight development

Initial and final body weights as well as daily body weight gain were greater in the obese control group and the obese carnitine group than in the lean control group $(P<0.05$; Table 3$)$. Similarly, feed intake was greater in the obese control group and the obese carnitine group than in the lean control group $(P<0.05$; Table 3$)$. The feed conversion ratio which describes gram feed per gram body weight gain was increased significantly in the lean control group $(P<0.05$; Table 3$)$. These parameters did not differ between the two obese groups.

\section{Concentration of carnitine in plasma and M. rectus femoris}

In line with recent observations, the obese control group had lower concentrations of free carnitine, acetylcarnitine and total carnitine (= sum of free carnitine and acetyl-carnitine) in plasma and rectus femoris muscle than the lean control group $(P<0.05$; Table 4$)$. Due to carnitine supplementation concentrations of free carnitine, acetyl-carnitine and total carnitine in plasma and rectus femoris muscle were greater in the obese carnitine group than in the lean control group $(P<0.05$; Table 4).

\section{Lipid concentrations in plasma and liver}

As expected, rats of the obese groups had greater levels of TG and NEFA in plasma and TG in the liver than those of the lean group $(P<0.05$; Table 4$)$. Due to carnitine supplementation, however, concentrations of TG and NEFA in plasma and TG in the liver were approximately $25-30 \%$ lower in the obese carnitine group than in the obese control group $(P<0.05$; Table 4$)$.

\section{Fiber type composition and expression of myosin heavy chain isoforms in $\mathbf{M}$. rectus femoris}

Muscle fiber typing revealed an approximately 18\% lower percentage of type I muscle fibers in rectus femoris muscle in the obese control group than in the lean control group. Interestingly, the type I muscle fiber percentage in rectus femoris muscle did not differ between the obese carnitine group and the lean control group indicating that carnitine supplementation prevented obesity-induced type I to type II fiber transition $(P<0.05$; Figure $1 \mathrm{~A}, \mathrm{~B})$. In contrast, the type II fiber percentage in rectus femoris muscle was greater in the obese control group than in the other two groups $(P<0.05$; Figure $1 \mathrm{~A}, \mathrm{~B})$, but it did not differ between the obese control group and the lean control group. The composition of muscle fiber types in rectus femoris muscle did not differ between the lean control 
Table 1 Characteristics of primers used for qPCR

\begin{tabular}{|c|c|c|c|c|c|c|}
\hline $\begin{array}{l}\text { Gene symbol } \\
\text { (HUGO) }\end{array}$ & $\begin{array}{l}\text { Primer sequence } \\
\text { (forward, reverse; from } 5 \text { ' to } 3^{\prime} \text { ) }\end{array}$ & $\begin{array}{l}\text { NCBI } \\
\text { GeneBank }\end{array}$ & $\begin{array}{l}\text { Product } \\
\text { size (bp) }\end{array}$ & Slope & $\mathrm{R}^{2 \#}$ & Efficiency* \\
\hline \multirow[t]{2}{*}{ ACADL } & AAGGATTTATTAAGGGCAAGAAGC & NM_012819 & $380 \mathrm{bp}$ & -3.88 & 0.998 & 1.81 \\
\hline & GGAAGCGGAGGCGGAGTC & & & & & \\
\hline \multirow[t]{2}{*}{ ACADM } & CAAGAGAGCCTGGGAACTTG & NM_016986 & 154 bp & -3.38 & 0.999 & 1.98 \\
\hline & CCCCAAAGAATTTGCTTCAA & & & & & \\
\hline \multirow[t]{2}{*}{ ATP5B } & GCACCGTCAGAACTATTGCT & NM_134364 & 203 bp & -3.59 & 0.999 & 1.90 \\
\hline & GAATTCAGGAGCCTCAGCAT & & & & & \\
\hline \multirow[t]{2}{*}{ CANX } & CCAGATGCAGATCTGAAGAC & NM_172008 & $175 \mathrm{bp}$ & -2.75 & 0.999 & 2.31 \\
\hline & CTGGGTCCTCAATTTCACGT & & & & & \\
\hline \multirow[t]{2}{*}{ CD36 } & TCGTATGGTGTGCTGGACAT & NM_031561 & 358 bp & -3.28 & 0.996 & 2.02 \\
\hline & GGCCCAGGAGCTTTATTITC & & & & & \\
\hline \multirow[t]{2}{*}{ CPT1B } & GCAAACTGGACCGAGAAGAG & NM_013200 & 180 bp & -3.32 & 0.988 & 2.00 \\
\hline & CCTTGAAGAAGCGACCTTTG & & & & & \\
\hline \multirow[t]{2}{*}{ FABP3 } & ACCATCCACTGCCGTCTTAC & NM_013177 & 310 bp & -3.20 & 0.957 & 2.05 \\
\hline & CCCCGATGCGTAGGTATTCT & & & & & \\
\hline \multirow[t]{2}{*}{ HK2 } & GATGGAATCGAGAAGGCCTA, & NM_012735 & 220 bp & -3.63 & 1.000 & 1.89 \\
\hline & GTTCTTGTAGACGGAGCCA & & & & & \\
\hline \multirow[t]{2}{*}{ LPL } & GAGATTTCTCTGTATGGCACA & NM_012598 & 276 bp & -3.34 & 0.992 & 1.99 \\
\hline & CTGCAGATGAGAAACTTTCTC & & & & & \\
\hline \multirow[t]{2}{*}{$\mathrm{MDH} 1$} & CAGACAAAGAAGAGGTTGCC, & NM_033235 & $206 \mathrm{bp}$ & -3.40 & 0.994 & 1.97 \\
\hline & CGTCAGGCAGTTTGTATTGG & & & & & \\
\hline \multirow[t]{2}{*}{ MYH1 } & GCAGACTCTCCCACTGGGCTG & NM_001135158 & $83 \mathrm{bp}$ & -3.16 & 0.953 & 2.07 \\
\hline & GAGCAGCCTCCCCGAAAACGG & & & & & \\
\hline \multirow[t]{2}{*}{$\mathrm{MYH} 2$} & GCTGATCGAAATGCTGCTGA & NM_001135157 & 124 bp & -3.38 & 0.990 & 1.98 \\
\hline & GTCAATAGCACTATCCGTGG & & & & & \\
\hline \multirow[t]{2}{*}{$\mathrm{MYH} 4$} & CCAGTCCATCCTGATTACTG & NM_019325 & $74 \mathrm{bp}$ & -3.48 & 0.988 & 1.94 \\
\hline & CAAAGTACTGGATGACACGC & & & & & \\
\hline \multirow[t]{2}{*}{ MYH7 } & ATTGCCGAGTCCCAGGTCAACA & NM_017240 & $127 \mathrm{bp}$ & -3.24 & 0.944 & 2.03 \\
\hline & GCTCCAGGTCTCAGGGCTTCAC & & & & & \\
\hline \multirow[t]{2}{*}{ PFKM } & TCCTGGTTGGCTCAATCGAC & NM_031715 & $297 \mathrm{bp}$ & -3.75 & 0.998 & 1.85 \\
\hline & TGTTGAGACGAGAACCACGG & & & & & \\
\hline \multirow[t]{2}{*}{ PKM } & ACCTGGGCATTGAGATTCCG & NM_053297 & 314 bp & -3.69 & 0.997 & 1.87 \\
\hline & TCGCGCAAGCTCTTCAAACA & & & & & \\
\hline \multirow[t]{2}{*}{ PPARD } & GCAGAGCTATGACCAGGCCTGCA & NM_013141 & $151 \mathrm{bp}$ & -3.29 & 0.990 & 2.01 \\
\hline & GTGCTCTGGTCCCCCGTTGA & & & & & \\
\hline \multirow[t]{2}{*}{ PPARGC1A } & СTCTTTGCCCAGATCTTCCT & NM_031347 & $145 \mathrm{bp}$ & -3.93 & 0.999 & 1.80 \\
\hline & ATGTTCGCGGGCTCATTGTT & & & & & \\
\hline \multirow[t]{2}{*}{ PPARGC1B } & CATATAAGCCCATGGAGGAG & NM_176075 & 476 bp & -3.25 & 0.978 & 2.03 \\
\hline & CAGCCCAAAGTGCTITGTGA & & & & & \\
\hline \multirow[t]{2}{*}{ RPL13 } & CTTAAATTGGCCACGCAGCT & XR_086310 & $198 \mathrm{bp}$ & -3.48 & 0.998 & 1.94 \\
\hline & CTTCTCAACGTCTTGCTCTG & & & & & \\
\hline \multirow[t]{2}{*}{$\mathrm{SDHA}$} & TGGACCTTGTCGTCTITGG & NM_130428 & $88 \mathrm{bp}$ & -3.90 & 0.997 & 1.80 \\
\hline & TाTGCCTTAATCGGAGGAAC & & & & & \\
\hline SLC2A4 & GAGTTATGTGTCCATCGTGG & NM_012751 & $187 \mathrm{bp}$ & -2.59 & 0.953 & 2.40 \\
\hline
\end{tabular}


Table 1 Characteristics of primers used for qPCR (Continued)

\begin{tabular}{|c|c|c|c|c|c|c|}
\hline & CGCAACATACTGGAAACCCA & & & & & \\
\hline \multirow[t]{2}{*}{ SLC22A5 } & GAACTCACGAGCCTCGCACGC & NM_019269 & $117 \mathrm{bp}$ & -3.75 & 0.997 & 1.85 \\
\hline & TCGTCGTAGTCCCGCATGCC & & & & & \\
\hline \multirow[t]{2}{*}{ SLC25A20 } & AGCCCACCTGTTATCCACTG & NM_053965 & $178 \mathrm{bp}$ & -3.32 & 0.988 & 2.00 \\
\hline & TGTGCAAAAAGAGCCTTCCT & & & & & \\
\hline \multirow[t]{2}{*}{ SLC27A1 } & GTATCTGCTGGACCTTCGC & NM_053580 & $243 \mathrm{bp}$ & -3.48 & 0.990 & 1.94 \\
\hline & CATAAATGAGGGCCTTGGCA & & & & & \\
\hline \multirow[t]{2}{*}{ TOP1 } & GAAGAACGCTATCCAGAAGG & NM_022615 & $137 \mathrm{bp}$ & -3.33 & 0.997 & 2.00 \\
\hline & GCTTTGGGACTCAGCTTCAT & & & & & \\
\hline \multirow[t]{2}{*}{ UCP1 } & CAGGCTTCCAGTACTATTAGG & NM_012682 & $181 \mathrm{bp}$ & -3.40 & 0.983 & 1.97 \\
\hline & СTCTCCCTGAAGAGAAGTACT & & & & & \\
\hline \multirow[t]{2}{*}{ UCP2 } & CAAGGAGAGAGTCAAGGGCTA & NM_019354 & $209 \mathrm{bp}$ & -3.08 & 0.998 & 2.11 \\
\hline & GACTCTGAGCCCTTGGTGTAG & & & & & \\
\hline \multirow[t]{2}{*}{ UCP3 } & CTCGGTACCATCCTGACTAT & NM_013167 & $149 \mathrm{bp}$ & -3.47 & 0.982 & 1.94 \\
\hline & GTTCCTTTGGGGGTGTAGAA & & & & & \\
\hline \multirow[t]{2}{*}{ VEGFA } & GTTCATGGACGTCTACCAGC & NM_031836 & $253 \mathrm{bp}$ & -3.62 & 0.973 & 1.89 \\
\hline & GCTATGCTGCAGGAAGCTCA & & & & & \\
\hline \multirow[t]{2}{*}{ VEGFB } & GTGTCCCAGTTTGATGGCC & NM_053549 & $187 \mathrm{bp}$ & -3.45 & 1.000 & 1.95 \\
\hline & CGTCAGGACAGCAGCCAC & & & & & \\
\hline \multirow[t]{2}{*}{ YWHAZ } & GACGGAAGGTGCTGAGAAA & NM_013011 & $198 \mathrm{bp}$ & -3.13 & 0.986 & 2.09 \\
\hline & GCAGCAACCTCAGCCAAGT & & & & & \\
\hline
\end{tabular}

${ }^{\#}$ Coefficient of determination of the standard curve.

*The efficiency is determined by $\left[10^{(-1 / \text {-slope }}\right]$.

and the obese carnitine group. Relative mRNA levels of genes encoding the different myosin heavy-chain II isoforms (MHCIIa encoded by MYH2, MHCIIb encoded by MYH4, MHCIIx encoded by MYH1) did not differ between the groups (Figure 1C). However, the relative mRNA level of MHCIb (encoded by MYH7), which encodes the type I fiber specific myosin heavy chain isoform; in rectus femoris muscle was greater in the lean control and the obese carnitine group than the obese control group $(P<0.05$; Figure $1 \mathrm{~B})$.

Table 2 Average expression stability ranking of six candidate reference genes

\begin{tabular}{lcc}
\hline Ranking & Gene & M value \\
\hline Most stable & YWHAZ & 0.056 \\
& TOP1 & 0.060 \\
CANX & 0.060 \\
MDH1 & 0.062 \\
Least stable & ATP5B & 0.073 \\
\hline
\end{tabular}

Ranking of the candidate reference genes according to their stability score $\mathrm{M}$ as calculated by the Microsoft Excel-based application GeNorm.
Expression of genes involved in muscle fiber transformation in $\mathrm{M}$. rectus femoris

The mRNA levels of the main regulators of muscle fiber transformation PPAR $\delta$ (encoded by PPARD), PGC- $1 \alpha$ (encoded by PPARGC1A) and PGC-1 $\beta$ (encoded by PPARGC1B) in rectus femoris muscle were greater in the obese carnitine than in obese control group $(P<0.05$; Table 5). The lean control and the obese control group did not differ with regard to these genes.

The relative protein level of $\mathrm{PGC}-1 \alpha$ in rectus femoris muscle was also greater in the obese carnitine group than in the obese control and the lean control group $(P<0.05$; Figure 2$)$. The relative protein level of PPAR $\delta$ in rectus femoris muscle was $33 \%$ higher in the obese carnitine group than in the obese control group but this effect was not significant (Figure 2).

\section{Expression of genes involved in carnitine uptake, fatty} acid transport, fatty acid utilization, and glycolysis in $\mathrm{M}$. rectus femoris

The mRNA levels of genes involved in carnitine uptake [SLC22A5 encoding organic cation/carnitine transporter (OCTN2)], fatty acid transport and uptake (FABP3 encoding fatty acid binding protein 3, CD36 encoding fatty acid translocase/CD36, LPL encoding lipoprotein lipase), 
Table 3 Feed intake and body weight gains of lean rats (lean control), obese Zucker rats fed a control diet (obese control) or obese Zucker rats fed a diet supplemented with $3 \mathrm{~g} / \mathbf{k g}$ diet carnitine (obese carnitine) for 4 wk ${ }^{1}$

\begin{tabular}{|c|c|c|c|}
\hline & $\begin{array}{c}\text { Lean } \\
\text { control }\end{array}$ & $\begin{array}{l}\text { Obese } \\
\text { control }\end{array}$ & $\begin{array}{c}\text { Obese } \\
\text { carnitine }\end{array}$ \\
\hline Feed intake $(\mathrm{g} / \mathrm{d})$ & $19.7 \pm 0.2^{c}$ & $25.2 \pm 0.5^{b}$ & $26.4 \pm 0.4^{a}$ \\
\hline Initial body weight (g) & $271 \pm 3^{b}$ & $357 \pm 6^{\mathrm{a}}$ & $358 \pm 7^{\mathrm{a}}$ \\
\hline Final body weight (g) & $367 \pm 4^{\mathrm{b}}$ & $501 \pm 7^{a}$ & $496 \pm 9^{a}$ \\
\hline Daily body weight gain (g) & $3.35 \pm 0.08^{b}$ & $5.03 \pm 0.13^{\mathrm{a}}$ & $4.85 \pm 0.14^{\mathrm{a}}$ \\
\hline Feed conversion ratio ( $\mathrm{g}$ feed/g body weight) & $5.90 \pm 0.11^{\mathrm{a}}$ & $5.02 \pm 0.09^{b}$ & $5.18 \pm 0.18^{b}$ \\
\hline
\end{tabular}

${ }^{1}$ Data are expressed as means \pm SEM, $\mathrm{n}=12$ rats/group. Means in a row without a common letter differ $(P<0.05)$.

$\beta$-oxidation (ACADL, ACADM encoding long chain acylCoA dehydrogenase and medium chain acyl-CoA dehydrogenase, respectively), carnitine shuttle (SLC25A20 encoding carnitine/acylcarnitine translocase), and glycolysis (HK2 encoding hexokinase 2) in rectus femoris muscle were greater in the obese carnitine group than in the obese control group $(P<0.05$; Table 5$)$. The mRNA levels of SLC27A1 encoding fatty acid transport protein, CPT1B (encoding carnitine-palmitoyl transferase 1b), SLC2A4 encoding glucose transporter-4, PKM (pyruvate kinase, muscle), and PFKM (encoding phosphofructokinase, muscle) in rectus femoris muscle were numerically greater in the obese carnitine group than in the obese control group, but the differences were not significant (Table 5).

Table 4 Plasma and muscle (M. rectus femoris) concentrations of carnitine, plasma concentrations of TG and NEFA and liver concentration of TG in lean rats (lean control), obese Zucker rats fed a control diet (obese control) or obese Zucker rats fed a diet supplemented with $3 \mathrm{~g} / \mathbf{k g}$ diet carnitine (obese carnitine) for $\mathbf{4} \mathbf{w k}^{\mathbf{1}}$

\begin{tabular}{|c|c|c|c|}
\hline & $\begin{array}{c}\text { Lean } \\
\text { control }\end{array}$ & $\begin{array}{l}\text { Obese } \\
\text { control }\end{array}$ & $\begin{array}{c}\text { Obese } \\
\text { carnitine }\end{array}$ \\
\hline \multicolumn{4}{|l|}{ Plasma ( $\mu \mathrm{mol} / \mathrm{l})$} \\
\hline Total carnitine & $62.3 \pm 1.9^{b}$ & $40.0 \pm 1.1^{c}$ & $90.5 \pm 2.9^{a}$ \\
\hline Free carnitine & $50.8 \pm 1.6^{b}$ & $33.7 \pm 1.2^{c}$ & $73.2 \pm 2.5^{a}$ \\
\hline Acetyl-carnitine & $11.5 \pm 0.9^{b}$ & $6.3 \pm 0.3^{c}$ & $17.3 \pm 0.8^{a}$ \\
\hline \multicolumn{4}{|c|}{ M. rectus femoris $(\mathrm{nmol} / \mathrm{g})$} \\
\hline Total carnitine & $919 \pm 13^{b}$ & $752 \pm 13^{c}$ & $1165 \pm 19^{a}$ \\
\hline Free carnitine & $742 \pm 12^{b}$ & $590 \pm 9^{c}$ & $937 \pm 21^{a}$ \\
\hline Acetyl-carnitine & $176 \pm 4^{b}$ & $161 \pm 4^{b}$ & $228 \pm 6^{a}$ \\
\hline \multicolumn{4}{|l|}{ Plasma (mmol/l) } \\
\hline TG & $1.42 \pm 0.06^{c}$ & $6.35 \pm 0.18^{a}$ & $4.42 \pm 0.26^{b}$ \\
\hline NEFA & $0.73 \pm 0.06^{c}$ & $3.53 \pm 0.16^{\mathrm{a}}$ & $2.41 \pm 0.18^{b}$ \\
\hline \multicolumn{4}{|l|}{ Liver ( $\mu \mathrm{mol} / \mathrm{g})$} \\
\hline TG & $10.2 \pm 0.9^{b}$ & $87.7 \pm 13.7^{\mathrm{a}}$ & $65.6 \pm 8.1^{a}$ \\
\hline
\end{tabular}

${ }^{1}$ Data are expressed as means $\pm S E M, n=12$ rats/group. Means in a row without a common letter differ $(P<0.05)$.
The relative protein level of OCTN2 in rectus femoris muscle was also greater in the obese carnitine group than in the other groups $(P<0.05$; Figure 3$)$.

Expression of genes involved in angiogenesis, tricarboxylic acid cycle and mitochondrial respiratory chain and thermo genesis in $\mathrm{M}$. rectus femoris Relative mRNA levels of genes encoding vascular endothelial growth factor $b$ (VEGFB), succinate dehydrogenase subunit A (SDHA) and uncoupling proteins (UCP1 and UCP2) in rectus femoris muscle were greater in the obese carnitine group than in the obese control and the lean control group $(P<0.05$; Table 6$)$. The mRNA level of UCP3 in rectus femoris muscle was numerically greater in the obese carnitine group than in the obese control and lean control group, but this effect was not significant (Table 6).

\section{Discussion}

In the present study we tested the hypothesis that carnitine supplementation to obese Zucker rats counteracts the obesity-induced muscle fiber transition from type I to type II and, thereby, improves fatty acid utilization in skeletal muscle. The dietary carnitine dosage $(3 \mathrm{~g} / \mathrm{kg}$ diet) fed to the rats related to 156 to $216 \mathrm{mg} / \mathrm{kg}$ body weight based on an average daily feed consumption of $26 \mathrm{~g}$ and a body weight of 360 (initial) to 500 (final) g. This carnitine dosage is slightly higher when compared to that used in clinical studies with human subjects with different metabolic disorders in which carnitine dosages of up to $4 \mathrm{~g} / \mathrm{d}$ corresponding to $60 \mathrm{mg} / \mathrm{kg}$ body weight for an individual weighing $70 \mathrm{~kg}$ were found to be effective [28]. A key finding of the present study is that carnitine supplementation to obese rats resulted in an increased number of type I fibers and a decreased number of type II fibers in rectus femoris muscle when compared to non-supplemented obese rats. This indicates that carnitine induces type II to type I fiber transition in femoris muscle of obese rats which was also confirmed by the finding that the type I fiber specific $\mathrm{MYH7}$ mRNA level in rectus femoris muscle was markedly elevated in the obese carnitine group. Interestingly, the 


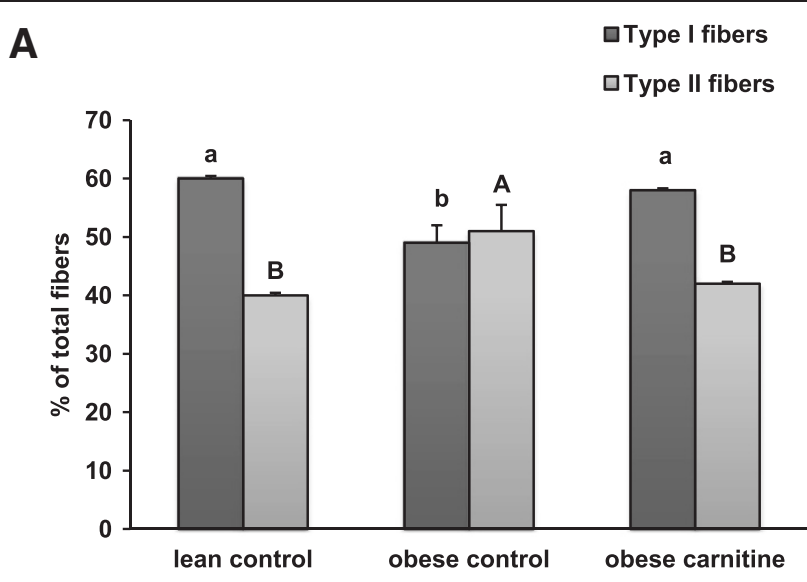

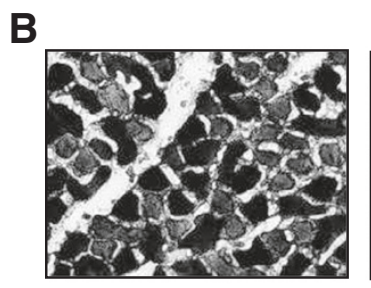

lean control

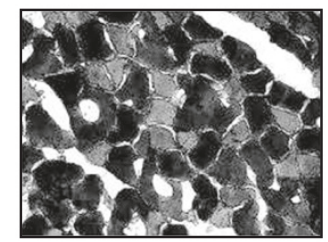

obese control

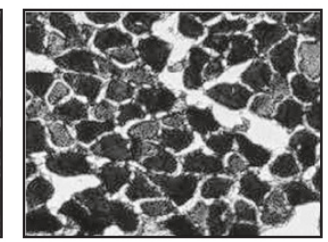

obese carnitine

\section{C}

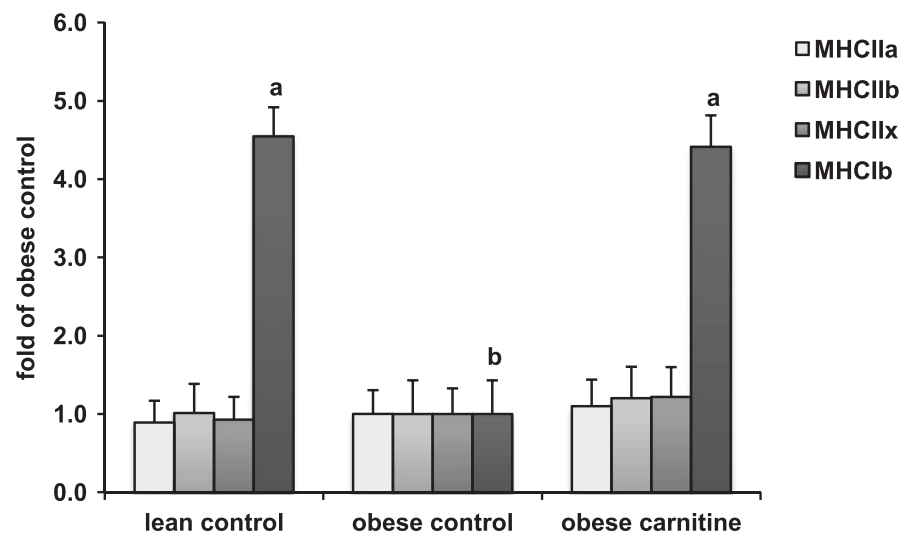

Figure 1 Fiber distribution of $M$. rectus femoris of lean rats (lean control), Zucker rats fed a control diet (obese control) or Zucker rats fed a diet supplemented with $\mathbf{3} \mathbf{~ g} / \mathbf{k g}$ diet carnitine (obese carnitine) for $\mathbf{4} \mathbf{w k}$. (A) muscle fiber type composition, (B) fiber type-specific cross-sectional area, $(\mathbf{C})$ relative $m R N A$ expression of myosine heavy chain isoforms. Bars represent means $\pm \mathrm{SEM}, \mathrm{n}=12$ rats/group. Means without a common letter differ $(P<0.05)$.

fiber type distribution of rectus femoris muscle was similar between the obese carnitine and the lean control group, whereas rectus femoris muscle of the obese control group had a lower number of type I fibers and a greater number of type II fibers compared to that of the lean control group. A reduction of type I fibers and a lower oxidative enzyme activity in muscle of obese and diabetic rodent models compared to lean models has been well documented [6,7]. In addition, several studies reported that obese subjects have a decreased proportion of type I muscle fibers and an overall decrease in mitochondrial enzymes indicating that muscle oxidative capacity is impaired in obese subjects [29-32], which likely contributes to the impaired whole body fatty acid utilization and the elevated blood lipid levels in these subjects. Moreover, it was shown that insulin sensitivity correlates positively with the proportion of type I muscle fibers and negatively with the proportion of type II muscle fibers [29-31]. There is a large body of evidence that carnitine supplementation improves glucose tolerance in insulin resistant and/or diabetic humans (reviewed by [28]). The observed up-regulation of genes in involved in glycolysis (HK2) by carnitine in muscle of the obese rats is also supportive of a beneficial effect of carnitine on glucose homeostasis. Insulin resistant and/or diabetic subjects are likely particularly sensitive to carnitine 
Table 5 Relative mRNA levels of genes involved in carnitine uptake, fatty acid transport, fatty acid utilization, and glucose uptake and glycolysis in $M$. rectus femoris of lean rats (lean control), obese Zucker rats fed a control diet (obese control) or obese Zucker rats fed a diet supplemented with $3 \mathbf{~ g} / \mathbf{k g}$ diet carnitine (obese carnitine) for $4 \mathbf{w k}^{1}$

\begin{tabular}{cccc}
\hline $\begin{array}{c}\text { Lean } \\
\text { control }\end{array}$ & $\begin{array}{c}\text { Obese } \\
\text { control }\end{array}$ & $\begin{array}{c}\text { Obese } \\
\text { carnitine }\end{array}$ \\
\hline \multicolumn{3}{c}{ Fold of obese control }
\end{tabular}

Muscle fiber transformation

\begin{tabular}{|c|c|c|c|}
\hline PPARD & $1.11 \pm 0.19^{b}$ & $1.00 \pm 0.12^{b}$ & $4.18 \pm 0.58^{a}$ \\
\hline PPARGC1A & $1.21 \pm 0.17^{b}$ & $1.00 \pm 0.16^{b}$ & $2.14 \pm 0.42^{a}$ \\
\hline PPARGC1B & $0.78 \pm 0.06^{\mathrm{b}}$ & $1.00 \pm 0.24^{b}$ & $2.02 \pm 0.24^{a}$ \\
\hline \multicolumn{4}{|c|}{ Carnitine uptake } \\
\hline SLC22A5 & $0.92 \pm 0.12^{\mathrm{b}}$ & $1.00 \pm 0.08^{b}$ & $1.90 \pm 0.25^{\mathrm{a}}$ \\
\hline \multicolumn{4}{|c|}{ Fatty acid transport and uptake } \\
\hline FABP3 & $1.05 \pm 0.28^{b}$ & $1.00 \pm 0.34^{\mathrm{b}}$ & $2.18 \pm 0.46^{\mathrm{a}}$ \\
\hline SLC27A1 & $1.19 \pm 0.34$ & $1.00 \pm 0.23$ & $1.46 \pm 0.30$ \\
\hline CD36 & $0.71 \pm 0.14^{\mathrm{b}}$ & $1.00 \pm 0.11^{b}$ & $1.52 \pm 0.20^{\mathrm{a}}$ \\
\hline LPL & $1.14 \pm 0.22^{b}$ & $1.00 \pm 0.28^{b}$ & $2.22 \pm 0.35^{a}$ \\
\hline \multicolumn{4}{|l|}{$\beta$-oxidation } \\
\hline ACADM & $1.79 \pm 0.44^{b}$ & $1.00 \pm 0.20^{b}$ & $3.39 \pm 0.86^{\mathrm{a}}$ \\
\hline ACADL & $1.11 \pm 0.23^{b}$ & $1.00 \pm 0.24^{b}$ & $2.25 \pm 0.61^{\mathrm{a}}$ \\
\hline \multicolumn{4}{|c|}{ Carnitine shuttle } \\
\hline CPT1B & $1.25 \pm 0.31$ & $1.00 \pm 0.35$ & $1.49 \pm 0.27$ \\
\hline SLC25A20 & $1.46 \pm 0.14^{\mathrm{a}}$ & $1.00 \pm 0.07^{b}$ & $1.39 \pm 0.13^{\mathrm{a}}$ \\
\hline \multicolumn{4}{|c|}{ Glucose uptake and glycolysis } \\
\hline SLC2A4 & $1.41 \pm 0.34$ & $1.00 \pm 0.32$ & $1.52 \pm 0.18$ \\
\hline $\mathrm{HK} 2$ & $1.32 \pm 0.37^{b}$ & $1.00 \pm 0.51^{\mathrm{b}}$ & $3.11 \pm 0.18^{a}$ \\
\hline PKM & $1.87 \pm 0.94$ & $1.00 \pm 0.33$ & $2.36 \pm 0.46$ \\
\hline PFKM & $1.20 \pm 0.51$ & $1.00 \pm 0.32$ & $1.23 \pm 0.25$ \\
\hline
\end{tabular}

${ }^{1}$ Data are expressed as means \pm SEM, $n=12$ rats/group. Means and SEM of the other groups were presented as fold of the obese control group, which mean was set to 1 . Means in a row without a common letter differ $(P<0.05)$.

supplementation because diabetic subjects were reported to have diminished plasma free carnitine concentrations, even though the levels were still within or only slightly below the physiological range $(25-50 \mu \mathrm{mol} / \mathrm{l})$ reported for healthy subjects [33-35]. Given the observed increase in type I muscle fiber proportion in obese rats and the relationship between type I muscle fiber proportion and insulin sensitivity it is not unlikely that the improvement of glucose tolerance and insulin sensitivity by carnitine supplementation in obese and diabetic subjects is due to the effect of carnitine on muscle fiber distribution. Even though a very recent study reported that carnitine supplementation at a non-physiologically high dosage promoted intestinal formation of the proatherogenic

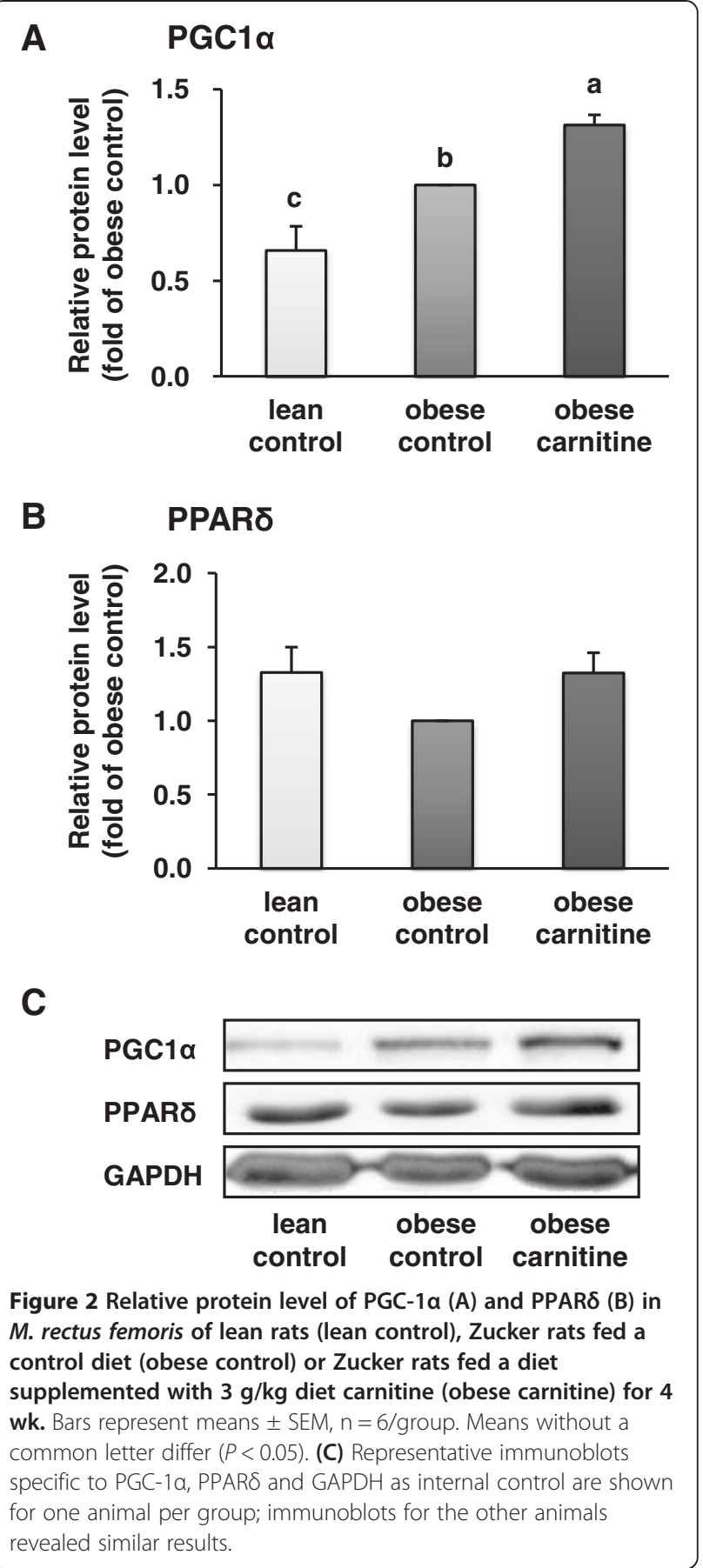

trimethylamine-N-oxide and accelerated atherosclerosis development in mice [36], the fact that none of the carnitine supplementation studies in humans reported any adverse effects even at very high dosages (e.g., $4 \mathrm{~g}$ oral carnitine) indicates that safety concerns with carnitine supplementation are unfounded. Collectively, the present findings corroborate our hypothesis that carnitine supplementation to obese rats counteracts the obesity-induced 


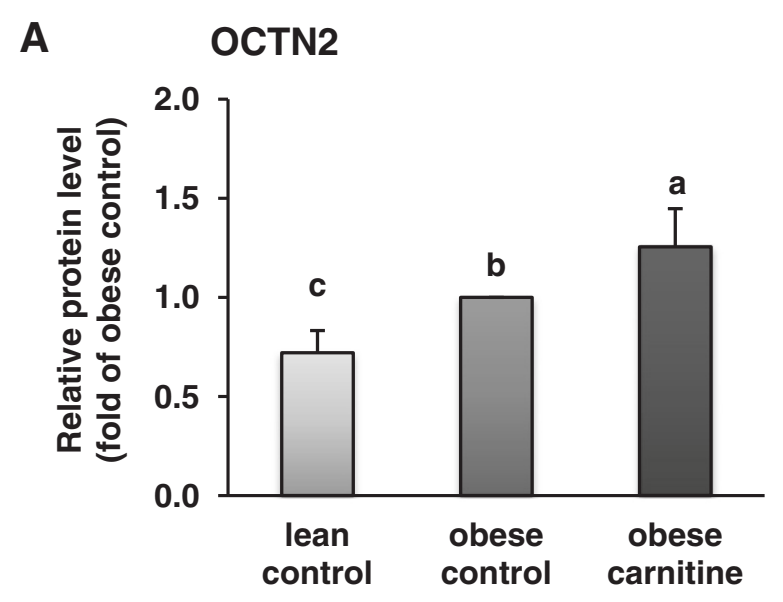

B

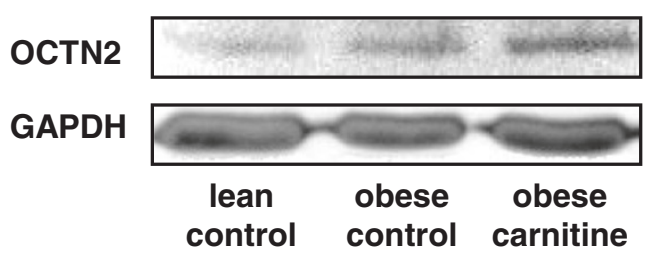

Figure 3 Relative protein level of OCTN2 in $M$. rectus femoris of lean rats (lean control), Zucker rats fed a control diet (obese control) or Zucker rats fed a diet supplemented with $3 \mathrm{~g} / \mathrm{kg}$ diet carnitine (obese carnitine) for $\mathbf{4}$ wk. (A) Bars represent means $\pm S E M, n=6 /$ group. Means without a common letter differ $(P<0.05)$. (B) Representative immunoblots specific to OCTN2 and GAPDH as internal control are shown for one animal per group; immunoblots for the other animals revealed similar results.

Table 6 Relative mRNA levels of genes involved in angiogenesis, mitochondrial respiratory chain and uncoupling proteins in $M$. rectus femoris of lean rats (lean control), obese Zucker rats fed a control diet (obese control) or obese Zucker rats fed a diet supplemented with $3 \mathrm{~g} / \mathbf{k g}$ diet carnitine (obese carnitine) for $\mathbf{4} \mathbf{w k}^{\mathbf{1}}$

\begin{tabular}{|c|c|c|c|}
\hline & $\begin{array}{l}\text { Lean } \\
\text { control }\end{array}$ & $\begin{array}{l}\text { Obese } \\
\text { control }\end{array}$ & $\begin{array}{c}\text { Obese } \\
\text { carnitine }\end{array}$ \\
\hline & \multicolumn{3}{|c|}{ Fold of obese control } \\
\hline \multicolumn{4}{|c|}{ Angiogenesis } \\
\hline VEGFA & $0.81 \pm 0.18$ & $1.00 \pm 0.30$ & $1.30 \pm 0.37$ \\
\hline VEGFB & $1.62 \pm 0.35^{\mathrm{ab}}$ & $1.00 \pm 0.19^{b}$ & $2.21 \pm 0.28^{a}$ \\
\hline \multicolumn{4}{|c|}{ TCA cycle and respiratory chain } \\
\hline SDHA & $1.26 \pm 0,25^{\mathrm{ab}}$ & $1.00 \pm 0.24^{b}$ & $2.18 \pm 0.40^{a}$ \\
\hline \multicolumn{4}{|c|}{ Thermogenesis } \\
\hline UCP1 & $1.67 \pm 0.35^{b}$ & $1.00 \pm 0.12^{b}$ & $7.06 \pm 1.27^{\mathrm{a}}$ \\
\hline UCP2 & $1.07 \pm 0.23^{b}$ & $1.00 \pm 0.24^{b}$ & $3.39 \pm 0.34^{a}$ \\
\hline UCP3 & $0.97 \pm 0.20$ & $1.00 \pm 0.25$ & $1.92 \pm 0.70$ \\
\hline
\end{tabular}

${ }^{1}$ Data are expressed as means \pm SEM, $n=12$ rats/group. Means and SEM of the other groups were presented as fold of the obese control group, which mean was set to 1 . Means in a row without a common letter differ $(P<0.05)$. muscle fiber transition from type I to type II and is able to restore the muscle fiber distribution and the oxidative metabolic phenotype observed in lean animals.

This study showed that carnitine supplementation in obese rodents resulted in a higher type I muscle fiber content compared to obese rats without carnitine supplementation. The observed decrease of carnitine levels in plasma and muscle in the obese control group is consistent with observations from recent studies showing that whole body carnitine status is strongly compromised in rodent models of genetic and diet-induced obesity and diabetes [10]. As the main reason for this phenomenon an impaired hepatic carnitine biosynthesis has been identified $[10,11]$. In contrast, carnitine supplementation to obese and/or diabetic rodent models is able to restore the carnitine status to normal [10] or even supraphysiological levels as shown herein. Although our observations do not proof a causal link between carnitine status and muscle fiber distribution, our results suggest that the carnitine-induced change in muscle fiber distribution is due to an improvement of carnitine status.

In addition, the present study shows that the carnitineinduced change in the contractile phenotype of skeletal muscle of obese rats is also accompanied by a change in the metabolic phenotype. In agreement with the high content of mitochondria and the preferential use of fatty acids for energy production of type I fibers, genes involved in fatty acid transport and uptake (FABP3, CD36, LPL), $\beta$-oxidation (ACADL, ACADM), carnitine shuttle (SLC25A20), carnitine uptake (SLC22A5) and TCA cycle and respiratory chain (SDHA) in femoris muscle were strongly up-regulated in the obese carnitine compared to the obese control group. In line with our findings in skeletal muscle, carnitine supplementation was also shown to stimulate TCA activity, mitochondrial respiration and ATP production in the diabetic rat heart $[37,38]$. Thus, these carnitine-induced effects on gene expression of rectus femoris muscle are indicative of an improved capacity of the muscle for oxidative utilization of fatty acids. Since skeletal muscle significantly contributes to whole-body fatty acid utilization, the improved oxidative metabolic phenotype of skeletal muscle at least partially explains the pronounced NEFA- and TG-lowering effects of carnitine supplementation observed in the present rat model of obesity and insulin resistance but also in other studies [39].

To gain insight into the mechanisms underlying muscle fiber transition we determined the mRNA and/ or protein levels of the main regulators of fiber composition. The two main regulators of type II to type I fiber transition, mitochondrial biogenesis, and oxidative enzyme expression, PPAR $\delta$ and PGC- $1 \alpha$, but also PGC- $1 \beta$, which induces similar effects as PGC-1 $\alpha$ on the contractile and metabolic phenotype of skeletal muscle 
$[40,41]$, were clearly stronger expressed in rectus femoris muscle of the obese carnitine group than in the obese control group. Regarding that PGC- $1 \alpha$ and PGC- $1 \beta$ also regulate angiogenesis through inducing the expression of angiogenic factors like VEGFs, we also determined transcript levels of VEGFA (encoding VEGFa) and VEGFB (encoding VEGFb). VEGFb particularly favors the utilization of fatty acids not only by increasing capillary density and thereby blood perfusion but also by inducing the expression of fatty acid transport proteins (FATPs, CD36) [42]. Correspondingly, VEGFb is mainly expressed in tissues with high mitochondria content and with preferential use of fatty acids as energy source like oxidative skeletal muscle, heart, and brown adipose tissue [43]. The observation that the relative mRNA level of VEGFB was markedly elevated in the obese carnitine group is therefore in line with the induction of PGC- $1 \alpha$ and PGC- $1 \beta$ and provides a further indication for the improved oxidative phenotype of rectus femoris muscle in rats of the obese carnitine group. Collectively, our findings strongly suggest that the upregulation of genes encoding PGC- $1 \alpha, \mathrm{PGC}-1 \beta$, and PPAR $\delta$ in rectus femoris muscle by L-carnitine supplementation is responsible for the observed type II to type I fiber transition and the oxidative metabolic phenotype of skeletal muscle of obese Zucker rats.

In conclusion, the results of this study demonstrate that carnitine supplementation to obese Zucker rats significantly improves carnitine status, counteracts the obesity-induced muscle fiber transition from type I to type II and favors an oxidative metabolic phenotype of skeletal muscle which preferentially uses fatty acids as energy source. The enhanced capacity of skeletal muscle to utilize fatty acids was demonstrated by the carnitineinduced up-regulation of genes involved in fatty acid uptake and transport, carnitine uptake, fatty acid $\beta$ oxidation, mitochondrial fatty acid uptake (carnitine shuttle system) and tricarboxylic acid cycle. These metabolic changes in skeletal muscle are likely to contribute to the pronounced NEFA- and TG-lowering effects of carnitine supplementation in obese Zucker rats. Therefore, carnitine supplementation is supposed to be beneficial for the treatment of elevated levels of metabolic fuels (e.g., fatty acids) which are frequently found in subjects with obesity, insulin resistance, diabetes or metabolic syndrome.

\section{Competing interests}

The authors declare that they have no competing interests.

\section{Authors' contributions}

$A C, R R$ and KE designed research and coordinated the study; $A C$ carried out the molecular biological analyses; EM carried out the carnitine analyses; AC, KK and FCM performed muscle fiber typing. AC and KE wrote the paper. KE had primary responsibility for final content. All authors read and approved the final manuscript.

\section{Author disclosures}

A. Couturier, R. Ringseis, F.-C. Mooren, K. Krüger, E. Most and K. Eder have no conflicts of interest.

\section{Author details}

${ }^{1}$ Institute of Animal Nutrition and Nutrition Physiology,

Justus-Liebig-University Giessen, Heinrich-Buff-Ring 26-32, 35390 Giessen, Germany. ${ }^{2}$ Department of Sports Medicine, Justus-Liebig-University Giessen, Kugelberg 62, 35394 Giessen, Germany.

Received: 16 April 2013 Accepted: 29 June 2013

Published: 10 July 2013

\section{References}

1. Pette D, Staron RS: Cellular and molecular diversities of mammalian skeletal muscle fibers. Rev Physiol Biochem Pharmacol 1990, 116:1-76.

2. Peter JB, Barnard RJ, Edgerton VR, Gillespie CA, Stempel KE: Metabolic profiles of three fiber types of skeletal muscle in guinea pigs and rabbits. Biochemistry 1972, 11:2627-2633.

3. Barnard RJ, Edgerton VR, Furukawa T, Peter JB: Histochemical, biochemical, and contractile properties of red, white, and intermediate fibers. Am J Physiol 1971, 220:410-414.

4. Cassano P, Sciancalepore AG, Pesce V, Flück M, Hoppeler H, Calvani M, Mosconi L, Cantatore P, Gadaleta MN: Acetyl-L-carnitine feeding to unloaded rats triggers in soleus muscle the coordinated expression of genes involved in mitochondrial biogenesis. Biochim Biophys Acta 2006, 1757:1421-1428.

5. Pesce V, Fracasso F, Musicco C, Lezza AMS, Cantatore P, Gadaleta MN: Acetyl-L-carnitine dietary supplementation to old rats increases mitochondrial transcription factor A content in rat hind limb skeletal muscles. Ann N Y Acad Sci 2004, 1019:430-433.

6. Fujita N, Nagatomo F, Murakami S, Kondo H, Ishihara A, Fujino H: Effects of hyperbaric oxygen on metabolic capacity of the skeletal muscle in type 2 diabetic rats with obesity. ScientificWorldJournal 2012, 2012:637978.

7. Nagatomo F, Fujino H, Kondo H, Gu N, Takeda I, Ishioka N, Tsuda K, Ishihara A: PGC-1a mRNA level and oxidative capacity of the plantaris muscle in rats with metabolic syndrome, hypertension, and type 2 diabetes. Acta Histochem Cytochem 2011, 44:73-80.

8. Grichko VP, Heywood-Cooksey A, Kidd KR, Fitts RH: Substrate profile in rat soleus muscle fibers after hind limb unloading and fatigue. J App/ Physiol 2000, 88:473-478.

9. Koves TR, Ussher JR, Noland RC, Slentz D, Mosedale M, Ilkayeva O, Bain J, Stevens R, Dyck JRB, Newgard CB, Lopaschuk GD, Muoio DM: Mitochondrial overload and incomplete fatty acid oxidation contribute to skeletal muscle insulin resistance. Cell Metab 2008, 7:45-56.

10. Noland RC, Koves TR, Seiler SE, Lum H, Lust RM, Ilkayeva O, Stevens RD, Hegardt FG, Muoio DM: Carnitine insufficiency caused by aging and over nutrition compromises mitochondrial performance and metabolic control. J Biol Chem 2009, 284:22840-22852.

11. Ringseis R, Mooren F, Keller J, Couturier A, Wen G, Hirche F, Stangl Gl, Eder K, Krüger K: Regular endurance exercise improves the diminished hepatic carnitine status in mice fed a high-fat diet. Mol Nutr Food Res 2011, 55 (Suppl 2):S193-S202.

12. Moriggi M, Cassano P, Vasso M, Capitanio D, Fania C, Musicco C, Pesce V, Gadaleta MN, Gelfi C: A DIGE approach for the assessment of rat soleus muscle changes during unloading: effect of acetyl-L-carnitine supplementation. Proteomics 2008, 8:3588-3604.

13. Power RA, Hulver MW, Zhang JY, Dubois J, Marchand RM, Ilkayeva O, Muoio DM, Mynatt RL: Carnitine revisited: potential use as adjunctive treatment in diabetes. Diabetologia 2007, 50:824-832.

14. Li D, Kang Q, Wang D: Constitutive co activator of peroxisome proliferator-activated receptor (PPAR $\gamma$ ), a novel co activator of PPAR that promotes adipogenesis. Mol Endocrinol 2007, 21:2320-2333.

15. Evans RM, Barish GD, Wang Y: PPARs and the complex journey to obesity. Nat Med 2004, 10:355-361.

16. Naya FJ, Mercer B, Shelton J, Richardson JA, Williams RS, Olson EN: Stimulation of slow skeletal muscle fiber gene expression by calcineurin in vivo. J Biol Chem 2000, 275:4545-4548.

17. Wu H, Kanatous SB, Thurmond FA, Gallardo T, Isotani E, Bassel-Duby R, Williams RS: Regulation of mitochondrial biogenesis in skeletal muscle by CaMK. Science 2002, 296:349-352. 
18. Pette D, Staron RS: Myosin isoforms, muscle fiber types, and transitions. Microsc Res Tech 2000, 50:500-509.

19. Lin J, Wu H, Tarr PT, Zhang C, Wu Z, Boss O, Michael LF, Puigserver P, Isotani E, Olson EN, Lowell BB, Bassel-Duby R, Spiegelman BM: Transcriptional coactivator PGC-1a drives the formation of slow-twitch muscle fibres. Nature 2002, 418:797-801.

20. Olson EN, Williams RS: Remodeling muscles with calcineurin. Bioessays 2000, 22:510-519.

21. Lin J, Handschin C, Spiegelman BM: Metabolic control through the PGC-1 family of transcription co activators. Cell Metab 2005, 1:361-370.

22. Reeves PG, Nielsen FH, Fahey GC: AIN-93 purified diets for laboratory rodents: final report of the American Institute of Nutrition ad hoc writing committee on the reformulation of the AIN-76A rodent diet. J Nutr 1993, 123:1939-1951.

23. Hämäläinen N, Pette $D$ : The histochemical profiles of fast fiber types IIB, IID, and IIA in skeletal muscles of mouse, rat, and rabbit. J Histochem Cytochem 1993, 41:733-743.

24. Ringseis R, Rosenbaum $S$, Gessner DK, Herges L, Kubens JF, Mooren F, Krüger K, Eder K: Supplementing obese zucker rats with niacin induces the transition of glycolytic to oxidative skeletal muscle fibers. J Nutr 2013, 143:125-131.

25. Ringseis $R$, Muschick A, Eder K: Dietary oxidized fat prevents ethanolinduced triacylglycerol accumulation and increases expression of PPARa target genes in rat liver. J Nutr 2007, 137:77-83.

26. Hirche F, Fischer M, Keller J, Eder K: Determination of carnitine, its short chain acyl esters and metabolic precursors trimethyllysine and gammabutyrobetaine by quasi-solid phase extraction and MS/MS detection. J Chromatogr B Analyt Technol Biomed Life Sci 2009, 877:2158-2162.

27. Keller J, Ringseis R, Koc A, Lukas I, Kluge H, Eder K: Supplementation with Icarnitine down regulates genes of the ubiquitin proteasome system in the skeletal muscle and liver of piglets. Animal 2012, 6:70-78.

28. Ringseis R, Keller J, Eder K: Role of carnitine in the regulation of glucose homeostasis and insulin sensitivity: evidence from in vivo and in vitro studies with carnitine supplementation and carnitine deficiency. Eur J Nutr 2012, 51:1-18.

29. Lillioja S, Young AA, Culter CL, IVy JL, Abbott WG, Zawadzki JK, Yki-Järvinen H, Christin L, Secomb TW, Bogardus C: Skeletal muscle capillary density and fiber type are possible determinants of in vivo insulin resistance in man. J Clin Invest 1987, 80:415-424.

30. Hickey MS, Carey JO, Azevedo JL, Houmard JA, Pories WJ, Israel RG, Dohm GL: Skeletal muscle fiber composition is related to adiposity and in vitro glucose transport rate in humans. Am J Physiol 1995, 268:E453-E457.

31. Mårin P, Andersson B, Krotkiewski M, Björntorp P: Muscle fiber composition and capillary density in women and men with NIDDM. Diabetes Care 1994, 17:382-386

32. Kriketos AD, Pan DA, Lillioja S, Cooney GJ, Baur LA, Milner MR, Sutton JR, Jenkins AB, Bogardus C, Storlien LH: Interrelationships between muscle morphology, insulin action, and adiposity. Am J Physiol 1996, 270:R1332-R1339.

33. De Palo E, Gatti R, Sicolo N, Padovan D, Vettor R, Federspil G: Plasma and urine free L-carnitine in human diabetes mellitus. Acta Diabetol Lat 1981, 18:91-95.

34. Winter Winter SC, Simon M, Zorn EM, Szabo-Aczel S, Vance WH, O'Hara T, Higashi L: Relative carnitine insufficiency in children with type I diabetes mellitus. Am J Dis Child 1989, 143:1337-1339.

35. Poorabbas Poorabbas A, Fallah F, Bagdadchi J, Mahdavi R, Aliasgarzadeh A, Asadi $Y$, Koushavar $\mathrm{H}$, Vahed Jabbari M: Determination of free L-carnitine levels in type II diabetic women with and without complications. Eur J Clin Nutr 2007, 61:892-895.

36. Koeth RA, Wang Z, Levison BS, Buffa JA, Org E, Sheehy BT, Britt EB, Fu X, Wu Y, Li L, Smith JD, Didonato JA, Chen J, Li H, Wu GD, Lewis JD, Warrier M, Brown JM, Krauss RM, Tang WH, Bushman FD, Lusis AJ, Hazen SL: Intestinal micro biota metabolism of I-carnitine, a nutrient in red meat, promotes atherosclerosis. Nat Med 2013, 19:576-585.

37. Broderick TL: ATP production and TCA activity are stimulated by propionyl-L-carnitine in the diabetic rat heart. Drugs R\&D 2008, 9:83-91.

38. Broderick TL, Haloftis G, Paulson DJ: L-propionylcarnitine enhancement of substrate oxidation and mitochondrial respiration in the diabetic rat heart. J Mol Cell Cardiol 1996, 28:331-340.
39. Liang $Y, L i$ Y, Shan J, Yu B, Ho Z: The effect of oral L-carnitine treatment on blood lipid metabolism and the body fat content in the diabetic patient. Asia Pacific J Clin Nutr 1998, 7:192-195.

40. Mortensen $\mathrm{OH}$, Frandsen L, Schjerling P, Nishimura E, Grunnet N: PGC-1a and PGC-1 $\beta$ have both similar and distinct effects on myofiber switching toward an oxidative phenotype. Am J Physiol Endocrinol Metab 2006, 291:E807-E816.

41. Arany Z, Lebrasseur N, Morris C, Smith E, Yang W, Ma Y, Chin S, Spiegelman $B M$ : The transcriptional co activator PGC-1 $\beta$ drives the formation of oxidative type IIX fibers in skeletal muscle. Cell Metab 2007, 5:35-46.

42. van der Vusse GJ, van Bilsen M, Glatz JF: Cardiac fatty acid uptake and transport in health and disease. Cardiovasc Res 2000, 45:279-293.

43. Hagberg CE, Falkevall A, Wang X, Larsson E, Huusko J, Nilsson I, van Meeteren LA, Samen E, Lu L, Vanwildemeersch M, Klar J, Genove G, Pietras K, Stone-Elander S, Claesson-Welsh L, Ylä-Herttuala S, Lindahl P, Eriksson U: Vascular endothelial growth factor $B$ controls endothelial fatty acid uptake. Nature 2010, 464:917-921.

\section{doi:10.1186/1743-7075-10-48}

Cite this article as: Couturier et al: Carnitine supplementation to obese Zucker rats prevents obesity-induced type I to type II muscle fiber transition and favors an oxidative phenotype of skeletal muscle. Nutrition \& Metabolism 2013 10:48.

\section{Submit your next manuscript to BioMed Central and take full advantage of:}

- Convenient online submission

- Thorough peer review

- No space constraints or color figure charges

- Immediate publication on acceptance

- Inclusion in PubMed, CAS, Scopus and Google Scholar

- Research which is freely available for redistribution 